\title{
Immigrants and Asylum Seekers' Digital Entrepreneurship Competence: Evaluation of the Theoretical Framework
}

\author{
Julija MELNIKOVA \\ Klaipeda University, Klaipeda, Lithuania \\ Julija.melnikova@ku.lt \\ Virginija JURGAITYTE \\ Klaipeda University, Klaipeda, Lithuania \\ svenska.ku@gmail.com \\ Jeḷena ZAŠČERINSKA \\ Centre for Education and Innovation Research, Riga, Latvia \\ iizi.info@inbox.lv \\ Ludmila ALEKSEJEVA \\ Centre for Education and Innovation Research, Riga, Latvia \\ vaset@inbox.lv \\ Art LEETE \\ Tartu University, Tartu, Estonia \\ art.leete@ut.ee \\ Helleka KOPPEL \\ Tartu University, Tartu, Estonia \\ helleka@antropoloogia.ee \\ Ingmarie ROHDIN \\ Folkuniversitetet, Kristianstad, Sweden \\ ingmarie.rohdin@folkuniversitetet.se \\ Asa Hedlin OLSSON \\ Folkuniversitetet, Kristianstad, Sweden \\ asa.hedlin-olsson@folkuniversitetet.se
}

\begin{abstract}
The article reveals the concept of digital entrepreneurship and its framework for education of immigrants and asylum seekers in Baltic Sea countries. The research has been carried out in the boundaries of the Nordplus Adult project with participation of partner organisations from Estonia, Latvia, Lithuania and Sweden. As stated in the article, digital entrepreneurship is supposed to be one of the opportunities in promoting successful integration of immigrants and asylum seekers into labour market. Therefore, by supporting the development of entrepreneurship as an integral part of adult education, and modelling new methods of combining new digital technologies and entrepreneurship education it is intended to help both immigrants and asylum seekers to acquire relevant competence for successful integration into labour markets. The article's purpose is to
\end{abstract}


disclose the relevance of digital entrepreneurship as a new competence of immigrants and asylum seekers with respect to their needs for successful integration into the socio-economic situation of a host country. The method of data collection was interview with experts. The experts found the efficiency of the framework important to some degree. In the experts' opinion, educational goals based on the framework are achievable. However, diversity of the target group could be a risky factor.

Keywords: Digital entrepreneurship, education of immigrants and asylum seekers, competence, Baltic Sea countries.

\section{INTRODUCTION}

As countries in Europe and beyond have faced a large influx of immigrants and asylum seekers, social and integration services have to take the immediate response and to provide sufficient support to integrate newcomers into the host society and get them on a path to economic self-sufficiency. The investments in labor market integration policies are especially compelling in countries facing demographic decline and skills shortages. Baltic countries face unbalance in their labour markets. On the one hand, there is unemployment (Estonia $-4.2 .0 \%$, Latvia $-7.3 \%$, Lithuania $-6.2 \%$, Eurostat 2019). On the other hand, many industries, in particular in the field of ICT, experience a shortage of skilled workforce. Another tendency is that immigrants in these countries continue to face great difficulties in finding employment, and are also more likely to be found working on shortterm, low-paid jobs which fail to fulfil their skills potential, moreover, entrepreneurial capabilities of immigrants are not sufficiently developed (Eurofound, 2017). Given the fact that immigrants and asylum seekers' employment potential in European countries is rather low (McHugh, \& Morawski, 2017) the new ways of integration should be developed especially those of fostering entrepreneurial competence. Advances in digitisation and developments in ICTs create opportunities for new types of entrepreneurial activities. One such type of entrepreneurial activity is digital entrepreneurship, defined as a new business creation opportunity generated by ICTs - internet, mobile technology, social computing and digital platforms. Digital entrepreneurship is supposed to become in future one of the opportunities in promoting the successful integration of immigrants and asylum seekers into labour market. Therefore, by supporting the development of entrepreneurship as an integral part of adult education, and by modelling new methods of combining new digital technologies, entrepreneurship education in Baltic countries it is intended to help both immigrants and asylum seekers to acquire relevant competence for successful integration into labour markets.

The aim of the article is to disclose the relevance of the digital entrepreneurship as a new competence of immigrants and asylum seekers with respect to their needs for successful integration into the socio-economic situation of a host country.

The methods applied: theoretical analysis, experts' evaluation (interview in a written form); interpretative content analysis.

\section{THEORETICAL BACKGROUND}

Digital entrepreneurship is defined as a practice of pursuing "new venture opportunities presented by new media and internet technologies" (Davidson, Vaast, 2010). It is similar to traditional entrepreneurship. Entrepreneurship is the capacity and willingness to develop, organize and manage a business venture along with any of its risks in order to make a profit. The most obvious example of entrepreneurship is the starting of new businesses. Entrepreneurial spirit is characterized by innovation and risk-taking, and is an essential part of a nation's ability to succeed in an ever changing and increasingly competitive global marketplace. It involves recognizing and seizing 
opportunities, transforming those opportunities into marketable goods or services, assuming risk, and realizing rewards, and may occur in a variety of settings, including new and old ventures, non-profit institutions, and the public sector (Man et al, 2002). Digital entrepreneurship - is a subcategory of entrepreneurship that leverages new technologies in novel ways such as the Internet Communications Technology. A digital entrepreneur is an individual who uses the Internet as a tool to create commercial opportunities, disseminate information, and collaborate with clients and partners (Nuthall, 2006). In the sense that "digital ventures aim at generating a financial profit and are directly inscribed into the economic realm, such as creation of a new company or commercialization of an innovation" (Davidson, Vaast, 2010). In digital entrepreneurship "some or all of the entrepreneurial venture takes place digitally instead of in more traditional formats" (Hair et al, 2012). Digital enterprises are different from traditional entrepreneurial ventures because they have different business models and can pursue their products, marketing and distribution activities using digital platforms.

In the article, we follow the "mild digital entrepreneurship" approach provided by Henry et al. (2007). Mild digital entrepreneurship means venturing into the digital economy as a supplement or complement to traditional setting. Digital ventures can use computerized technologies as the main means of communications within their organization, between the organization and their key stakeholders (for example, suppliers and customers), or both (Valenzuela, 2000). Entrepreneurial competencies have been identified as a specific group of competencies relevant to the exercise of successful entrepreneurship. Such entrepreneurship is often associated with the development of small and new businesses (Heilbrunn, Kushnirovich, 2007; Nuthall, 2006). Digital entrepreneurship competencies have been defined as the total ability of the entrepreneur to perform a job role successfully using a range of ICT means. There is a general consensus that entrepreneurial competencies are carried by individuals, who begin and transform their businesses.

The set of entrepreneurial competencies has been identified by different researchers (Man et al. 2002; Hull et al. 2007). The classifications usually include opportunity, relationship, conceptual, organizing, strategic, and commitment competencies. The studies of digital entrepreneurship (Heilbrunn, Kushnirovich, 2007; Nuthall, 2006) allowed the authors of the article to add the framework with digital-based entrepreneurship competencies. As the result the theoretical framework of immigrants and asylum seekers' digital entrepreneurship competence has been developed. The framework includes:

1. The opportunity competencies are related to identifying, assessing and seeking market opportunities: identification and definition of a viable market niche; development of products/services appropriate to chosen market niche/innovation; idea generation; environmental scanning; recognising and envisioning taking advantage of opportunities; formulating strategies for taking advantage of opportunities.

2. The organizing competencies are related to managerial functions such as planning, organizing, leading and controlling: development of the management system necessary for long-term functioning of the organisation; acquisition and development of resources required; business operational skills; involvement with start-ups; financial and budgeting skills; management style; marketing skills; industry skills; the ability to implement strategy (develop programmes, budgets, procedures, evaluate performance); market analysis skills; business plan preparation skills; goal setting skills.

3. The relationship competencies embrace the ability to build, keep and use networks with stakeholders: development of organisational culture management system; delegation skills; collaboration skills; the ability to motivate others (individuals and groups); personnel management skills; human relation skills; leadership skills.

4. The conceptual competencies refer to creative thinking, innovative behaviour, assessment of risk etc.: creative thinking; innovativeness; organisational skills; interpersonal skills; emotional intelligence; the ability to manage customers; coordination skills; written communication skills; oral communication skills; decision making skills; analytical skills; logical thinking; critical thinking; deal-making skills. 
5. The strategic competencies deal with setting, evaluating, and implementing strategies of a venture: strategic management skills; vision and goals setting skills; research and analysis skills; data management; decision making skills; developing of the monitoring systems; quality assessment skills.

6. The commitment competencies are the abilities that drive the entrepreneur to work hard and face the difficulties involved in sustaining the business: sustainable leadership skills; team building; coaching and mentoring; personal development; commitment to excellence; persuasive techniques; trustworthiness; change management.

7. The digital-based entrepreneurship competencies: using the potential of network-based business; care about technological developments and market dynamics; maximum use of information technologies and supply management improvement; innovation management and implementation.

\section{EMPIRICAL STUDY}

The present part of the contribution demonstrates the design of the empirical study, results of the empirical study and findings of the study.

The empirical study has been carried out in the period between $201809-2018$ 11, by project "Adult educators' competence training for development of immigrants and asylum seekers' digital entrepreneurship" (funded for Nordplus Adult programme) team. Project partners from Estonia, Latvia, Lithuania and Sweden have carried out expert evaluation of the theoretical framework of the digital entrepreneurship competence. 5 external experts, who have an experience in working with and educating immigrants and asylum seekers ( 2 form Lithuania and 1 from each other country), analysed the developed framework and evaluated it according to the following criteria (developed by project team):

Authenticity - the degree the competence is needed by the target groups in the future workplaces.

Meaningfulness - the degree the framework will have some value for both teachers, learners and future stakeholders.

Fairness - the degree the framework will give the opportunity for future target groups' students to demonstrate their abilities and maximise their potential.

Transparency - the degree the framework if clear and understandable to all learning participants.

Generalisability - the degree the framework could be generalized to broader student domains.

Cognitive complexity - the degree the thinking processes will be applied by future target group students in the learning process.

Educational consequences - the degree the framework complies with the goals of education and is adjusted to learning and teaching activities accordingly.

Directness - the degree the framework will allow to assess the learning outcomes of the future students.

Comparability - the degree the teaching and learning activities based on the framework could be conducted in a consistent and responsible way with respect to other educational practices.

Efficiency - the degree the teaching learning goals based on the competence framework could be achieved.

Respondents' cultural and educational experience emphasized the significance of each participant's opinion on research question (Luka, Ludborza, Maslo, 2009) within the present empirical study. It should be noted that opinion is determined as individual's view based on awareness and attitudes (Lūka, 2007). The group of research participants was considered to be homogeneous.

The exploratory type of the comparative study (Phillips, 2006) was applied within the present empirical study. The exploratory type of the comparative study aims to generate new hypotheses and questions. The exploratory methodology proceeds (Phillips, 2006):

- 'conceptualisation' in Phase 1,

- detailed description of educational phenomena in the countries to be investigated features in Phase 2,

- the data collection in Phase 3, 
- explanation through the development of hypotheses in Phase 4,

- re-consideration of the initial questions and application of the findings to other situations in Phase 5.

The method of data collection was interview in a written form (Mayring, 2004).

The interpretive paradigm was used in the empirical study. The interpretive paradigm aims to understand other cultures, from the inside through the use of ethnographic methods such as informal interviewing and participant observation, and establishment of ethically sound relationships (Mayring, 2004). The interpretative paradigm creates an environment for the development of any individual and helps them to develop their potential (Lūka, 2008, 52). The core of this paradigm is human experience, people's mutual everyday interaction that tends to understand the subjectivity of human experience (Lūka, 2007). The paradigm is aimed at understanding people's activity, how a certain activity is exposed in a certain environment, time, conditions, i.e., how it is exposed in a certain socio-cultural context (Lūka, 2007). Thus, the interpretative paradigm is oriented towards one's conscious activity, and it is future-oriented. Interpretative paradigm is characterized by the researcher's practical interest in the research question. The researcher is the interpreter. After the answers were received the content analysis has been carried out.

\section{RESULTS OF THE EMPIRICAL STUDY}

First, it was sought to learn the authentic experience of experts in the field of immigrants and asylum seekers' education.

1. What is your experience in working with immigrants and asylum seekers?

All 5 experts have an experience of working and educating immigrants and asylum seekers. Estonian expert represents one of the leading competence centres on forced migration and refugee integration in Estonia. The centre offers various support for the integration of immigrants and asylums seekers by training, sharing and bringing good practices to Estonia, improving the Estonian reception and integration systems through advocacy, and sharing fact-based information to the broader public. In addition to providing trainings to education workers, the centre is also regularly improving the capacity of other specialists working with refugees, such as support persons, social workers and youth workers.

Expert form Latvia is involved in educational programmes for immigrants and asylum seekers provided by the centre for life-long learning that belong to the University in Latvia, Riga.

Experts from Lithuania represent the infocentre for support of migrants located in Klaipeda. Both experts are involved in various programmes that are aimed at rendering various kind of support (social cultural, educational etc.) for migrants.

Expert form Estonia represents the adult education organisation that has long experience working with migrants and asylum seekers and have different activities and programs for this target group. Moreover, the centre arranges lectures, exhibitions, cultural events, study circles and workshops and have created a meeting place where target groups can find possibilities to learn more about Sweden's society and to learn the Swedish language.

2. In your opinion, is the digital entrepreneurship competence relevant for immigrants and asylum seekers in your country?

All 5 experts agreed that digital entrepreneurship competence is relevant for immigrants and asylum seekers in order to enter the labour market more effectively. As the Swedish expert mentions: "to become an active citizen you need to have these skills". However, as Estonian expert emphasizes: "It's certainly relevant but one needs to consider the fact that digital skills of refugees are extremely different. Some of them start to get acquainted with computers here; some have previous experience of social media and Internet, and a few are even more skilled. Anyhow, there exists always a need for improving digital competences". As Lithuanian exerts mention "adult educators should bear in mind these differences and design the courses respectfully".

3. Does the development of digital entrepreneurship skills take place in educational programmes for immigrants and asylum seekers in your country? 
Lithuanian experts also stress that new skills of the digital entrepreneurship could be beneficial in order to foster the integration of immigrants and asylum seekers into labour market, however they suppose that educational programmes in this field are quite new and should be developed methodologically. The expert from Latvia also considers this field as a new one. To the mind of Latvian expert "the development of digital entrepreneurship skills is at a start point". Estonian expert mentions: "We offer assistance for starting with enterprises (at the moment we initiate a new social enterprise where the refugees have a leading position). On the other hand, we provide support for acquiring digital skills. But we do not combine these two fields explicitly. So far, nobody has indicated any interest towards this field of entrepreneurship. All business ideas have been from more traditional areas (food industry, cosmetics etc.)".

The evaluation of the competence framework according to the criteria listed above is presented in the table 1 in which " $X$ " means how many experts supported this particular choice:

Table 1: The evaluation of the competence framework according to the extracted criteria

\begin{tabular}{|l|c|c|c|}
\hline Criterion & To a high degree & To some degree & To a small degree \\
\hline Authenticity & $\mathrm{x}$ & $\mathrm{xxx}$ & $\mathrm{x}$ \\
\hline Meaningfulness & $\mathrm{xxx}$ & $\mathrm{xx}$ & \\
\hline Fairness & $\mathrm{xxxx}$ & $\mathrm{x}$ & \\
\hline Transparency & $\mathrm{x}$ & $\mathrm{xxxx}$ & \\
\hline Generalisability & $\mathrm{xx} \mathrm{xxx}$ & \\
\hline Cognitive complexity & $\mathrm{x}$ & $\mathrm{xx}$ & \\
\hline $\begin{array}{l}\text { Educational } \\
\text { consequences }\end{array}$ & & $\mathrm{xxxx}$ & \\
\hline Directness & $\mathrm{xxx}$ & $\mathrm{xxxxx}$ & \\
\hline Comparability & $\mathrm{xx}$ & $\mathrm{xx}$ & \\
\hline Efficiency & & $\mathrm{xxx}$ & \\
\hline
\end{tabular}

The authenticity of the framework was at the average defined by experts as being "to some degree" important. In the opinion of informants "the importance of the framework will increase as soon as training programmes in this field appear". Research participants stressed that "presently nobody offers such kind of training therefore it is rather difficult to predict its added value for future workplaces".

The meaningfulness of the competence framework was assessed as important "to a high degree". Experts emphasized that the value of the framework will increase in the learning process directly.

The fairness of the competence framework was evaluated to a higher degree. To the mind of respondents, the framework is highly up-to-day and relevant for target groups. Therefore, adult educators might expect high interest from the target groups.

The transparency of the framework was assessed as average. Respondents mentioned that "the framework and its advantages and disadvantages will become clear in the process of teachinglearning". According to experts "It is clear that something new will be proposed. Anyhow, it is tricky to predict future".

The generalisability of the framework was assessed as average. Respondents emphasized that the target groups if very diverse. Therefore, it is a great challenge for adult educators to develop courses respectfully to the differences of the target groups participants.

The cognitive complexity was evaluated as rather important. "From the students' point of view, it seems rather challenging. Everybody can benefit but it may be also challenging to everybody. Both entrepreneurship and digital competences are highly important fields in education but one needs to combine those adequately".

The aspect of educational consequences was defined as average. In the opinion of the research participants "it is hard to predict but, perhaps, it gives some tools for such assessment educational 
outcomes". The framework could be compared with study programs that already exist. "In principle, it seems promising field but as no such programs have been implemented earlier, we cannot really tell".

The aspect of directness was evaluated as "important to some degree". In the opinion of informants, the competence framework could be applied to the needs of another target groups for instance: unemployed, university and college graduates etc.

The comparability was assessed as very important. As mentioned above, experts emphasized the possibility to apply the developed framework in the development of training courses for another target groups.

The efficiency of the framework was determined as to some degree important. In the opinion of the experts, educational goals that are based on the framework are achievable, however, educators should bear in mind that the diversity of the target group could be a risky factor and some means for avoiding risks should be anticipated.

\section{IMPLICATIONS}

Digital entrepreneurship is defined as a new business creation opportunity generated by ICTs internet, mobile technology, social computing and digital platforms. Digital entrepreneurship is supposed to become in future one of the opportunities in promoting the successful integration of immigrants and asylum seekers into labour market. Therefore, by supporting the development of entrepreneurship as an integral part of adult education, and by modelling new methods of combining new digital technologies, entrepreneurship education in Baltic countries it is intended to help both immigrants and asylum seekers to acquire relevant competence for successful integration into labour markets.

The "mild digital entrepreneurship" approach provided by Hull et al. (2007) is followed. Mild digital entrepreneurship means venturing into the digital economy as a supplement or complement to traditional setting. Digital ventures can use computerized technologies as the main means of communications within their organization, between the organization and their key stakeholders.

Entrepreneurial competencies have been identified as a specific group of competencies relevant to the exercise of successful entrepreneurship. A set of entrepreneurial competencies that includes opportunity, relationship, conceptual, organizing, strategic, commitment competencies and digitalbased entrepreneurship has been highlighted.

The competence framework has received rather positive evaluation from experts, who are involved in immigrants and asylum seekers' educational programmes. The framework was assessed on the basis of certain criteria that allowed to evaluate its value and appropriateness for the educational processes.

\section{ACKNOWLEDGEMENT}

The present work has been carried out within the Nordplus Adult project 2018 entitled "Adult Educators' Competence Training for Development of Immigrants and Asylum Seekers' Digital Entrepreneurship".

\section{REFERENCES}

Davidson, E., \& Vaast, E. (2010). Digital Entrepreneurship and its Sociomaterial Enactment. Paper presented at 43rd Hawaii International Conference on System Sciences (HICSS), 5-8 January 2010.

European Foundation for the Improvement of Living and Working Conditions (Eurofound). (2017). Annual review of working life 2017. Retrieved March 25, 2019 from https://www.eurofound.europa.eu/publications/report/2018/annual-review-of-working-life-2017. 
Eurostat. (2019). Unemployment rates, seasonally adjusted, January 2019 (\%). Retrieved March 25, 2019 from https://ec.europa.eu/eurostat/statistics-explained/index.php/Unemployment_statistics.

Hair, N., Wetsch, L. R., Hull, C. E., Perotti, V., \& Hung, Y-T. C. (2012). Market Orientation in Digital Entrepreneurship: Advantages and Challenges in A Web 2.0 Networked World. International Journal of Innovation and Technology Management, 9(6).

Heilbrunn, N., \& Kushnirovich, S. (2007). Immigrant and indigenous enterprises: Similarities and differences. International Journal of Business Performance Management, 9(3) (2007), pp. 344-36.

Henry, C., Hill, F. \& Leitch, C. (2007). Entrepreneurship Education and Training. Ashgate, Aldershot.

Hull, C.E., Hung, Y.-T.C., Hair, N., Perotti, V. \& DeMartino, R. (2007). Taking advantage of digital opportunities: a typology of digital entrepreneurship, International Journal of Networking and Virtual Organisations, 4(3):290-303.

Lūka, I. (2007). Students and the educator's co-operation as a means of development of students' ESP competence. Paper presented at the European Conference on Educational Research, University of Goteborg, 10-12 September 2008. Retrieved March 25, 2019, from http://www.leeds.ac.uk/educol/documents/172916.htm

Lūka, I. (2008). Development of Students' ESP Competence and Educator's Professional Activity in Tertiary Level Tourism Studies. Proceedings of ATEE Spring University Conference Teacher of the 21st Century: Quality Education for Quality Teaching (pp. 689-697). Riga: University of Latvia.

Luka, I., Ludborza, S., \& Maslo, I. (2009). Effectiveness of the use of more than two languages and quality assurance in European interuniversity master studies. Paper presented at the European Conference on Educational Research, University of Vienna, September 28-30, 2009.

Man, T.W.Y., Lau, T., \& Chan, K.F. (2002). The competitiveness of small and medium enterprises: a conceptualization with focus on entrepreneurial competencies. Journal of Business Venturing 17, $123-142$.

Mayring, Ph. (2004). Qualitative Content Analysis. Flick, U., von Kardoff, E., Steinke, I. (Eds.) $A$ Companion to Qualitative Research, pp. 266-269. SAGE, Glasgow, UK, (2004).

McHugh, M., \& Morawski, M. (2017). Unlocking Skills: Successful Initiatives for Integrating Foreign-Trained Immigrant Professionals. Washington DC: Migration Policy Institute. Retrieved March 25, 2019 from https://www.migrationpolicy.org/research/unlocking-skills-successfulinitiatives-integrating-foreign-trained-immigrant-professionals.

Nuthall, G. (2006). Taking advantage of digital opportunities: a typology of digital entrepreneurship", International Journal of Networking and Virtual Organisations, Vol. 4 No. 3, pp. 290-303. [Crossref], [Google Scholar] [Infotrieve].

Phillips, D. (2006). Comparative Education: method. Research in Comparative and International Education, Volume 1, Number 4, 2006, 304-319.

Valenzuela, A. Jr. (2000). Working on the margins: Immigrant day labor characteristics and prospects for employment. Working Paper of the University of California, Los Angeles (No. 22). 